\title{
La représentation des français dans le roman intitulé La Maison de lumière de Nourredine Saadi
}

\section{Representation of the French in Nourredine Saadi's novel $L a$ Maison de lumière}

\author{
Ayşe TOMAT YILMAZ1 (1)
}

${ }^{1}$ Attaché of Education, Dr., Ministry of Education, Turkish Consulate General in Lyon Office of the Educational Attaché, Lyon, France

ORCID: A.T.Y. 0000-0001-8631-2854

Corresponding author: Ayşe TOMAT YILMAZ,

T.C. Millî Eğitim Bakanlığı, T.C. Liyon Başkonsolosluğu Eğitim Ataşeliği, Lyon, Fransa

E-mail: ayse_tomat@hotmail.com

Submitted: 20.03 .2021

Accepted: 27.06 .2021

Citation: Tomat Yilmaz, A. (2021). La représentation des français dans le roman intitulé La Maison de lumière de Nourredine Saadi. Litera, 31(2), 667-686. https://doi.org/10.26650/LITERA2021-900446

\section{RÉSUMÉ}

L'imagologie qui émerge comme sous-discipline des études de littérature comparée et qui analyse des représentations de l'étranger dans des œuvres littéraires suscite un grand intérêt dans le monde littéraire. Pour cette raison, de nombreux livres et articles sont écrits à la fois sur l'imagologie et sur l'image d'un group, d'une société ou d'une nation. L'une des sociétés en question sur laquelle sont menées des études imagologiques est celle des Français. Il ne fait aucun doute qu'il existe de nombreuses images des Français qui ont profondément marqué des sociétés à travers l'histoire et que ces images se reflètent également dans des œuvres littéraires. Les français qui ont dominé l'Algérie entre 1830 et 1962 ont laissé de nombreuses images positives et négatives dans la conscience collective du peuple algérien. Dans ce contexte, ce présent travail vise à révéler les traces et les représentations des Français dans le roman intitulé La Maison de lumière de Nourredine Saadi qui est l'un des écrivains les plus connus de la littérature algérienne francophone. L'objectif de ce travail est aussi de montrer les représentations des Français, en d'autres termes, la perception de l'Autre et de sa culture dans le contexte imagologique de Daniel-Henri Pageaux, spécialiste de littérature comparée.

Mots-clés: La littérature comparée, l'imagologie, la littérature algérienne francophone, La Maison de lumière, l'Autre

\section{ABSTRACT}

Imagology, which emerges as a sub-branch of comparative literature and analyses the representations of the foreigner in literary works, arouses great interest in the literary world. For this reason, many books and articles have been written both on imagology and on the imagery of a group, a society or a nation. One of the societies in question on which imagological studies are carried out is that of the French. There is no doubt that there are many imageries concerning the French, who have deeply affected various societies throughout history, and these imageries are reflected in the literary works as well. The French, who dominated Algeria between 1830-1962, left many positive and negative imageries in the collective memory of the Algerian people. In this context, the present study aims to investigate the traces and the representations of French in the novel entitled La Maison de lumière of Nourredine 
Saadi, who is one of the best-known writers of Francophone Algerian literature. This study further aims to examine Saadi's representations of the French (in other words, the perception and culture of the Other) in the context of the imagological approach of Daniel-Henri Pageaux, specialist in comparative literature.

Keywords: Comparative literature, imagology, francophone algerian literature, La Maison de lumière, the Other

\section{EXTENDED ABSTRACT}

Imagology, which was first used in 1962 by Oliver Brachfeld in his article entitled "Note sur l'imagologie ethnique", shortly thereafter began to be applied to literary studies by Belgian comparatist Hugo Dyserinck. After this, the first studies in this field appeared and the imagology spread first in Europe and then in other countries. In time, imagology aroused great interest in the literary world and many researchers and specialists turned to this discipline.

Imagology creates an interdisciplinary field of research by associating with many disciplines and is defined in different ways by researchers and specialists. It is generally defined as a science which aims to reveal the imageries of the foreigner in literary works. In other words, it deals with the subject of the Other and focuses on the image of the foreigner.

Daniel-Henri Pageaux, a specialist in comparative literature, writes on imagology in his book entitled La littérature générale et comparée, published by Armand Colin in 1994. In this book, Pageaux presents a method that consists of three levels for studying the imageries of the Other: the word, the hierarchical relationship, and the scenario. The present work aims to examine the representations of French in the novel entitled La Maison de lumière by Nourredine Saadi in the context of the imagological approach of Daniel-Henri Pageaux.

Nourredine Saadi, one of the best-known writers of Francophone Algerian literature, describes historical facts fictitiously in his novel. While telling the story of a house built in Algiers, Saadi chronologically describes the change of Algeria from the time of the Ottoman Empire until the early nineties. He narrates the period of Hussein Dey, the appearance of French settlers in Algeria, their sovereignty for 132 years, the Algerian war of independence and the departure of the French. In addition, he explicates the happiness, sorrows, sufferings and mourning of the Algerian people. In this context, it 
is possible to say that Saadi benefits from the collective memory of the Algerian people and presents the historical, sociological and political description of his country in his novel.

Since La Maison de lumière narrates a period of around two centuries, the novel encounters positive and negative imageries from many different societies. However, in this work, only French imageries are mentioned. Investigation of Saadi's representation of the French (or the perception of the Other) in the context of Pageux's imagological approach reveals many imageries of the Other. Using both historical and fictional characters, Saadi conveys the imageries of the French in the eyes of himself and wider Algerian society. His book itself further shows the culture of the Other to his readers, as it contains many imageries of French culture.

The analyses based on the perception and culture of the Other in this work show that Saadi defines the French by using both positive and negative imageries. In other words, the French, or the Other, have both positive and negative imageries in the collective memory of the Algerians. The examples reveal that there is a close relationship between the Algerian people and the French. Some Algerian characters really like the French, as they have lived together for many years. On the other hand, in some cases, other Algerian characters aren't happy to live with the French because they think that the French have taken control of their country. As a result, it is clear that the French, with both positive and negative imageries in the eyes of the Algerians, deeply affected the Algerian people and left their traces in the country during the period they lived together. 
Les jugements que portent les nations les unes sur les autres nous informent sur ceux qui parlent, non sur ceux dont on parle.

(Todorov, 1989, p. 32)

\section{Introduction}

L'Algérie qui abrita tout au long de l'histoire de nombreuses civilisations telles que celle des Berbères, des Arabes, des Ottomans et des Français attire des écrivains et enrichit leurs mondes imaginaires. Parmi ces écrivains, on peut compter Nourredine Saadi, écrivain algérien et universitaire, qui dessine généralement la situation historique, culturelle et économique de l'Algérie dans ses œuvres. Dans son deuxième roman intitulé La Maison de lumière, Saadi décrit chronologiquement toute l'histoire de l'Algérie de l'époque ottomane jusqu'au début des années quatre-vingt-dix en relatant l'histoire d'une maison, construite par le vizir du Trésor du Dey d'Alger. Durant cette période qui couvre environ deux siècles, il met l'accent sur l'invasion coloniale française, sa souveraineté dans la région pendant cent trente-deux ans, la guerre d'Algérie et le départ des Français.

Dans ce contexte, ce travail vise à présenter l'image des Français et les aspects de I'altérité dans La Maison de lumière en se servant de l'approche imagologique de DanielHenri Pageaux. En d'autres termes, cette étude s'attarde sur la représentation des Français à travers les yeux des Algériens dans le roman en question.

\section{Qu'est-ce que l'imagologie ?}

L'imagologie, l'une des branches de la littérature comparée, suscite un grand intérêt dans le monde littéraire dès sa première utilisation en 1962 par Oliver Brachfeld (Brachfeld, 1962) et est abordée par de nombreux chercheurs et spécialistes tels que Hugo Dyserinck, Yves Chevrel, Jean-Marc Moura, Daniel-Henri Pageaux et Serhat Ulağlı. Alors, qu'est-ce que l'imagologie qui attire autant l'attention ?

L'imagologie qui est forgée « pour regrouper les études portant sur les représentations de l'autre, de l'étranger » (Chevrel, 2009, p. 28) est « l'étude des représentations de l'étranger dans la littérature » (Moura, 1998, p. 35). Pageaux, spécialiste de littérature comparée, souligne que l'imagologie est « l'étude des images ou représentation de l'étranger » (Pageaux, 1994, p. 59) alors que Ulağlı la définit comme une science qui « 
recherche la différence entre le monde « fictif » formé avec des stéréotypes et le monde « réel » » (Ulağlı, 2018, p. 35). Il est donc possible de dire que l'imagologie se penche sur l'image de l'étranger dans les œuvres littéraires. Elle se fonde sur les images de I'Autre et les montre. En outre, elle observe de façon attentive et minutieuse le processus de la production de ces images. Autrement dit, «l'imagologie examine non seulement la structure des images mais aussi leurs formations » (Ulağlı, 2018, p. 35).

L'imagologie est généralement considérée comme une science interdisciplinaire parce qu'il existe des affinités entre cette méthode et l'histoire, la sociologie, la littérature, I'anthropologie, l'ethnologie, la philosophie, etc. En d'autres termes, l'étude imagologique « recoupe des recherches faites par des ethnologues, des anthropologues, des sociologues, des historiens des mentalités et des sensibilités, lesquels abordent des questions portant sur des cultures 'autres', sur l'altérité, sur l'identité, l'acculturation, la déculturation, l'aliénation culturelle, l'opinion publique ou l'imaginaire social » (Pageaux, 1994, p. 59). Pour cette raison, des comparatistes ou des imagologues doivent acquérir une connaissance littéraire, historique, sociologique, artistique, etc., et avoir un savoir-faire culturel.

Le matériau des études imagologiques est l'image, l'un des dénominateurs communs de nombreux domaines. «L'image est une structure significative créée par les relations entre réalité et imagination, faux et correct, subjectif et objectif, passé et aujourd'hui » (Ulağll, 2018, p. 8). Selon Pageaux, « toute image procède d'une prise de conscience, si minime soit-elle, d'un Je par rapport à un Autre, d'un Ici par rapport à un Ailleurs » (Pageaux, 1994, p. 60). Pageaux indique ainsi que l'image de l'Autre (la culture regardée) est étudiée en s'appuyant sur Je (la culture regardante).

Les images transmises de génération en génération depuis des siècles présentent à la fois l'Autre aux yeux de Je et permettent l'opportunité d'accéder au monde de Je car l'écrivain - le narrateur - la culture regardante - Je révèle en fait soi-même en définissant l'Autre. Dans ce contexte, il est possible de noter que «l'image est une traduction de l'Autre et aussi une autotraduction » (Pageaux, 1994, p. 65). Pour Pageaux,

Je regarde l'Autre et l'image de l'Autre véhicule aussi une certaine image de ce Je qui regarde, parle, écrit. Impossible d'éviter que l'image de l'Autre, à un niveau individuel (un écrivain), collectif (une société, un pays, une nation) ou semi-collectif (une famille de pensée une opinion, une littérature) n'apparaisse aussi comme la négation de l'Autre, le complément et le 
prolongement du Je et de son espace. Le Je veut dire l'Autre (pour d'impérieuses et complexes raisons, le plus souvent), mais en disant l'Autre, le Je tend à le nier et se dit soi-même. (Pageaux, 1994, p. 61)

Il est donc possible de dire que Je et l'Autre sont indissociables. Si l'Autre est primitif, Je est moderne, si la culture regardée est ignorante, la culture regardante est savante, si l'Autre est vieux, Je est jeune etc.

Par ailleurs, il faut mentionner un autre point très important. L'image qui se trouve dans des œuvres littéraires est à la fois un reflet de la réalité et de la fiction. L'auteur révèle d'une part l'esprit social, culturel, idéologique et politique de sa propre société en utilisant les images dans ses œuvres. II présente d'autre part les images en les remodelant dans son propre monde d'imagination selon sa propre perspective et sa propre façon de voir. C'est-à-dire que les images sont transmises après avoir traversé le filtre imaginaire de l'auteur. Dans ce cas, il est parfois impossible de déterminer si l'image reflète complètement la vérité.

Comme on le voit, l'imagologie révèle l'image d'une société ou d'une nation dans la littérature d'une autre nation et s'attache également à l'analyse des représentations de l'Autre. En outre, elle ouvre la possibilité de montrer les idées d'un auteur et de sa société sur un groupe, une société ou une nation à travers des images.

\section{La Maison de lumière}

Nourredine Saadi raconte des évènements historiques de manière fictive en utilisant un vocabulaire riche et orné dans son roman intitulé La Maison de lumière, dédié en grande partie à l'histoire de l'Algérie. Il dessine la période de Hussein Dey, I'apparition des colons français en Algérie, leur souveraineté pendant cent trente-deux ans, la guerre d'indépendance algérienne, le départ des Français et les évènements politiques. En bref, il montre les changements radicaux de son pays aux lecteurs. De cette manière, ceux-ci ont d'une part le sentiment de faire une promenade dans les rues de la ville d'Alger et sont d'autre part les témoins de la vie quotidienne du peuple. En outre, le roman décrit de nombreuses images différentes telles que celles des Ottomans, des Français, des Juifs et des Kabyles. Parmi elles, on se concentrera sur l'image des Français en se référant à l'analyse imagologique de Daniel-Henri Pageaux. 
Pageaux, auteur de nombreuses études sur l'image de l'Espagne et du Portugal, propose une méthode pour des études imagologiques dans son livre intitulé La littérature générale et comparée. Selon lui, l'image de l'Autre dans les œuvres littéraires peut être examinée en trois étapes : le mot, la relation hiérarchisée et le scénario (Pageaux, 1994, p. 64).

Pour la première étape de cette approche, il faut faire une liste des mots utilisés dans le roman en question. Pageaux divise ces mots en deux groupes : les mots-clés et les mots-fantasmes. Les premiers sont utilisés par l'écrivain - le narrateur - la culture regardante - Je pour décrire les personnages - la culture regardée - l'Autre. Les motsclés utilisés par Saadi dans son roman pour définir les Français sont à la fois positifs et négatifs. Par exemple, l'écrivain parle parfois de la bienveillance (Saadi, 2000, p. 96), de la générosité (Saadi, 2000, p. 198), de la modernité (Saadi, 2000, p. 77) des Français. Par contre, dans certains cas, il préfère utiliser plusieurs fois des mots tels que occupants (Saadi, 2000, p. 66,68,69), chrétiens (Saadi, 2000, p. 65,66,69,70) et géants blonds (Saadi, 2000, p. 173). De surcroît, il écrit de temps en temps « maudit pays » (Saadi, 2000, p. 150) au lieu de France.

En ce qui concerne les mots-fantasmes qui sont « pris à la langue du pays regardé » (Pageaux, 1994, p. 64), il est difficile de les préciser parce que l'écrivain rédige son œuvre en français. C'est pour cette raison qu'on ne peut pas les trouver. Toutefois, les mots-clés sont suffisants pour dégager la relation entre la culture regardée et regardante. II est exact que les mots-clés montrent à la fois une relation étroite entre le peuple algérien et les Français, « l'assimilation (I'Autre semblable, peu différent de Je) » (Pageaux, 1994, p. 65) et une haine « la différenciation (l'Autre opposé à Je) » (Pageaux, 1994, p. 65).

\section{Cadre spatio-temporel}

Il est question d'une analyse anthropologique des mots ci-dessus dans la deuxième étape, la relation hiérarchisée. À ce stade, Pageaux propose de traiter le sujet du cadre spatio-temporel. Dans ce contexte, il convient tout d'abord d'analyser l'espace dans lequel est défini l'Autre.

La Maison de lumière se déroule à Alger, la capitale de l'Algérie. Alger, la plus grande ville du pays, attire l'attention avec ses maisons blanches et ses rues étroites. Cette ville, parfois décrite comme «la Ville des Villes» (Saadi, 2000, p. 22) ou « la Ville Blanche» (Saadi, 2000, pp. 74-75) dans le roman, est une ville magique selon l'écrivain. 
Elle est vêtue d'un voile blanc sur son corps diaphane comme une fée, des pierres précieuses au cou, des perles aux oreilles et elle tient à la main, en forme d'entonnoir, comme du sable qui glisse dans sa paume, de la farine et du blé qui se répandent généreux sur la terre. (Saadi, 2000, pp. 23-24)

L'écrivain parle souvent de la beauté d'Alger et il la dépeint de façon détaillée. De plus, il tente d'expliquer à quoi ressemble la ville à travers les yeux des colons français. Selon eux, " des terres vierges offertes à tous les bras, du soleil d'or qui coule comme des poussières de safran toute l'année, des fruits comme vous n'en aurez jamais vu et des palmiers, des dromadaires, des déserts aux dunes douces comme les flancs de vos femmes »(Saadi, 2000, pp. 74-75).

Il existe de nombreuses descriptions de l'espace dans le roman. Mais, le point le plus important qui doit être souligné à ce sujet est la différence entre le village des colons et celui des colonisés. Par exemple, dans le Village indigène, celui des Algériens, on trouve « de petites bâtisses collées les unes aux autres comme des bêtes apeurées »(Saadi, 2000, p. 92) tandis que dans le Village blanc, celui des colons, les maisons blanches avec balcons se situent face à la mer. Les gens qui habitent dans le Village indigène ne peuvent pas entrer dans le village des colons sauf les ouvriers.

"La ville du colonisé, ou du moins la ville indigène, le village nègre, la médina, la réserve est un lieu mal famé, peuplé d'hommes mal famés. On y naît n'importe où, n'importe comment. On y meurt n'importe où, de n'importe quoi » (Fanon, 2002, p. 42). Il est exact que dans ce bidonville, les gens ne peuvent pas avoir assez de nourriture alors que les colons peuvent manger ceux qu'ils veulent. Ces Français nourrissent également bien leurs chiens. Ces bêtes sont trop grosses dans le Village blanc (Saadi, 2000, p. 194). En même temps, les Algériens marchent pieds nus alors que les colons français portent des chaussures (Saadi, 2000, p. 171). De plus, les colons emportent la richesse de l'Algérie en France. «Des tonneaux, des sacs, des colis sautaient des camions ouverts au ciel et passaient de main en main sur le navire. On aurait dit qu'ils emportaient tout le pays, alors que nous vivions dans la misère » (Saadi, 2000, p. 142).

Comme les gens ou les animaux, les enfants des deux villages ne peuvent jamais avoir des droits égaux. Par exemple, les enfants du Village indigène ont toujours des problèmes tels que la nourriture, les vêtements, etc. En outre, les différences entre les 
écoles des deux villages les attristent. Dans l'école coranique, qu'on appelle Jamaa, ils ne s'asseyent que par terre alors qu'ils peuvent être assis sur un banc dans l'École Voltaire. Mais ces enfants ne peuvent jamais s'asseoir sur le même banc que les enfants des Français. Il convient même d'ajouter que les enfants, dérangés par le froid humide dans les salles de l'école coranique, sont heureux dans les salles chauffées de l'École Voltaire (Saadi, 2000, pp. 202-203).

Les langues parlées sont aussi différentes dans ces deux villages, à la fois très proches et très éloignés l'un de l'autre. «Au Village indigène les uns parlaient en arabe, d'autres en kabyle. Au Village blanc, où l'on parlait français, se mêlaient des bribes d'italien, d'espagnol, de maltais » (Saadi, 2000, p. 202). En bref, comme l'affirme Fanon :

La ville du colon est une ville en dur, toute de pierre et de fer. C'est une ville illuminée, asphaltée, où les poubelles regorgent toujours de restes inconnus, jamais vus, même pas rêvés. Les pieds du colon ne sont jamais aperçus, sauf peut-être dans la mer, mais on n'est jamais assez proche d'eux. Des pieds protégés par des chaussures solides alors que les rues de leur ville sont nettes, lisses, sans trous, sans cailloux. La ville du colon est une ville repue, paresseuse, son ventre est plein de bonnes choses à l'état permanent. La ville du colon est une ville de blancs, d'étrangers. (Fanon, 2002, p. 42)

Quand les descriptions de la ville d'Alger et de ces deux villages sont comparées avec la vraie ville, on peut constater que l'espace décrit dans La Maison de lumière correspond à la réalité car comme on le sait, Alger qui possède un grand port de la côte méditerranéenne est connue pour ses maisons blanches, sa mer et ses belles plages. En ce qui concerne les différences entre deux villages, il semble pertinent de dire que la culture regardante ne méprise jamais l'espace de la culture regardée. Par contre, il est certain que Je désire vivre comme l'Autre.

Suite à l'espace, il faut analyser le temps du roman. Selon l'approche imagologique de Pageaux, ce qui est " proposé pour l'espace vaut aussi pour le temps » (Pageaux, 1994, p. 68). Comme le note Beïda Chikhi, les écrivains algériens francophones écrivent généralement des livres « liés à la forte histoire de leur société et à ses transmutations accélérées » (Chikhi, 1997, p. 9). Parmi eux, Saadi raconte, lui aussi les événements qui se déroulent de la dernière période de la souveraineté de l'Empire ottoman à Alger 
jusqu'aux années 1990. Durant cette période de deux siècles, il insiste particulièrement sur l'époque de l'Empire colonial français en Algérie.

Il est bien connu que l'Empire colonial français, constamment en conflit d'intérêts avec ses rivaux anglais, a commencé à s'intéresser de près à l'Algérie et l'a envahie en 1830. Dans le roman, les Algériens se souviennent « avec horreur de l'arrivée des chrétiens » (Saadi, 2000, p. 66). Les femmes âgées racontent sans cesse à leurs enfants "cet envahissement de géants blonds piétinant leurs couches et le souvenir des soldats leur déchirant les voiles ou palpant leurs visages pour toucher leur tatouages » (Saadi, 2000, p. 66).

Suite à leur victoire, les Français s'y installent de façon permanente. Marc Ferro précise que la population des Français a atteint 2379 personnes entre 1871 et 1881 en Algérie (Ferro, 1994, p. 116). Dans le roman, des centaines de Français arrivent en Algérie par bateau. Ces voyageurs, " tous massés derrière le bastingage criaient, hurlaient, sautaient de joie, saluant la terre par de larges mouvements des bras : La Ville Blanche, La Ville Blanche, La colonie !» (Saadi, 2000, p. 74).

Ces Français, venus avec le rêve de devenir riche, ont un autre désir : la femme orientale c'est-à-dire « une Fatma » (Saadi, 2000, p. 74). Pour eux, cette femme qu'ils rencontrent souvent dans les œuvres des voyageurs européens est exotique parce que «la figure de la femme exotique, sensuelle et fatale (dont le prototype est sans doute Salomé), devient progressivement un stéréotype au XIXe siècle, où elle constitue l'un des grands attraits du voyage en Orient (de Nerval à Flaubert ou Loti) » (Moura, 1992, p. 104). Ces femmes et leurs noms n'ont aucune importance aux yeux des colons. Ceux-ci rêvent seulement de les découvrir. À la lumière de toutes ces données, il est facile de conclure que le temps de l'histoire est compatible avec le temps réel, tout comme l'espace.

\section{Les personnages}

Pageaux précise que « l'espace et le temps ne sont pas seulement générateurs de pittoresque descriptif : ils peuvent entretenir avec le système des personnages, avec le narrateur, avec le Je, substitut parfois de l'écrivain homme public, des rapports explicatifs » (Pageaux, 1995, p. 143). À ce stade, suite au cadre spatio-temporel, il importe d'analyser le système des personnages (leur sexe, leur appartenance culturelle, politique, sociologique, etc.). 
II ne faut pas oublier qu'« en traitant le monde de la perception de l'écrivain dans une œuvre littéraire, l'imagologie accorde plus d'attention aux personnages créés par l'écrivain » (Ulağlı, 2018, p. 96). Autrement dit, l'analyse des personnages revêt une importance extrême parce qu'« un personnage n'est pas seulement un personnage fictif créé par l'écrivain, mais un vrai personnage créé par des éléments sociaux et psychologiques » (Ulağlı, 2018, p. 96). Dans ce contexte, on abordera les personnages dans le roman de Saadi pour déceler les idées de la société de l'écrivain sur les Français.

À cet égard, avant de traiter les personnages français un par un, il convient de dévoiler de façon générale les images positives et négatives des Français dans le roman. En ce qui concerne les images positives, il faut parler de leur supériorité technologique. Les colons français apportent avec eux « des machines, de bizarres appareils » (Saadi, 2000, p. 77) en Algérie. Le peuple algérien se sent étranger à ces machines qu'il voit pour la première fois. Cette situation prouve la supériorité technologique et économique des Français.

Un autre exemple frappant de ces images est la bienveillance des colons. Des années après l'installation des Français à Alger, dans le village indigène, une épidémie apparaît : le Typhus.

Les yeux fiévreux, les corps brûlants. Les traces de vipères sillonnaient la terre sèche et l'on voyait les femmes déterrer des racines pour les décoctions. Les gendarmes arrivèrent un matin et encerclèrent le Village indigène par des fils barbelés. La quarantaine ! Personne ne pouvait plus sortir. Ils apportèrent des sacs de farine et des jerricans d'eau, qu'ils jetaient pardessus les chevaux de frise. (Saadi, 2000, p. 95)

Le chaos surgit dans le village : certains commencent à se soulever et tentent de s'échapper, d'autres essayent de se révolter et des vieux lisent toute la journée les hadiths du Prophète. Mais un jour, des sœurs blanches viennent au Village indigène pour aider le peuple algérien même si au début celui-ci n'accepte pas de les appeler « ma sœur ». En prenant soin de leur santé, les sœurs parviennent à les guérir et à endiguer l'épidémie. Comme le montrent les exemples ci-dessus, il existe des images positives des Français aux yeux des Algériens dans le roman. 
II ne faut pas oublier que des images négatives existent également pour définir les Français. Ces images négatives créées par l'écrivain et sa société peuvent être associées au colonialisme car dans le roman de Saadi, les Français sont généralement désignés comme " dédaigneux », « cruels » et « oppresseurs ».

On sait que tout au long de l'histoire chaque colonisateur méprise généralement les colonisés parce que selon les colons européens «l'Oriental est déraisonnable, dépravé (déchu), puéril, différent ; l'Européen est ainsi raisonnable, vertueux, mûr, normal » (Said, 2005, p. 55). En d'autres termes, les colons sont « civilisés » et « intellectuels » tandis que les colonisés sont « primitifs ». Les colons français qui s'installent en Algérie dédaignent également le peuple algérien. Ils pensent que ce pays a besoin de réformes (Saadi, 2000, p. 140) et que le peuple doit être assimilé. Pour cette raison, les Français apportent des innovations et ignorent les traditions, la culture et la langue de l'Algérie.

Dans ce processus d'assimilation, la langue joue le rôle le plus efficace. Dans le roman, le sujet de la langue et les problèmes linguistiques des enfants algériens sont fréquemment mentionnés. "La maîtresse nous interdisait de parler arabe ou kabyle en classe et le plus difficile pour moi était de m'habituer à nommer chaque chose par deux noms : le nom de l'école et celui, kabyle, de la maison. Parfois trois car certaines choses n'existaient qu'en arabe » (Saadi, 2000, p. 203).

Ces enfants ont des difficultés pour apprendre cette nouvelle langue. Quand l'un de ces enfants fait des erreurs linguistiques, leur maîtresse d'école fronce ses sourcils, l'insulte et lui dit qu'il est « imbécile » (Saadi, 2000, p. 204). Bien que les enfants essayent de faire des dictées de temps en temps, apprendre le français est vraiment difficile pour eux.

Les colons qui obligent les colonisés à parler la langue française les font travailler dur parce qu'« il est plus économique d'utiliser trois colonisés qu'un Européen » (Memmi, 1973, p. 155). Dans le livre, les Français font combattre les Algériens à leur côté dans une guerre. De nombreux Algériens qui ne savent même pas pourquoi ils combattent meurent à la guerre. L'un d'eux est le père de Marabout, l'un des personnages du roman. Il n'a jamais connu son père parce qu'il est né pendant la guerre (Saadi, 2000, p. 115). Le corps de son père est apporté " dans une boîte entourée d'un drapeau » (Saadi, 2000 , p. 116) de la France. Sa mère qui reste longtemps muette déchire ce drapeau français la nuit. La France s'occupe de Marabout mais il dit qu'il ne savait pas qui était la France qui l'avait fait naître sans père (Saadi, 2000, p. 117). 
On sait qu'il existe de nombreuses insultes à l'égard des Arabes. Dans le roman, les colons utilisent aussi le mot « merle » pour définir les Algériens. « Certains des miliciens se sont vantés d'avoir fait des hécatombes comme à l'ouverture de la chasse. L'un d'eux aurait tué à lui seul quatre-vingt-trois merles » (Saadi, 2000, p. 189). Tous ces exemples montrent les images négatives des Français aux yeux des colonisés.

\section{Colonel Albin Saint-Aubin}

Comme déjà mentionné, La Maison de lumière couvre environ deux siècles. C'est pour cette raison qu'il existe de nombreux personnages des Ottomans aux Français, des Juifs aux Arabes. Mais, étant donné que le présent travail vise à montrer les images des Français, il faut donc parler des personnages français.

Parmi ces personnages du roman, le colonel Albin Saint-Aubin attire beaucoup l'attention parce que l'écrivain n'utilise presque aucune image négative pour le définir. Dans cette partie qui permet de dégager l'image des Français dans la conscience collective du peuple algérien, les images positives du Colonel Albin Saint-Aubin revêtent une grande importance.

Le colonel, un soldat couronné de succès, participe aux guerres dans l'armée française tout au long de sa vie. Le 5 avril 1918, il perd son bras gauche à cause d'un « éclat d'obus au Plessis » (Saadi, 2000, p. 140) et est nommé Commandant de la Légion d'honneur. Malgré la perte de son bras, il continue à travailler.

Un jour, Albin Saint-Aubin va à Alger pour son travail et il est fasciné par la beauté de cette ville. Pour cette raison, il veut acheter une demeure qui est construite par Mehmet Essaïdji ben Othman, le vizir du Trésor du Dey d'Alger. La maison est nommée «Miroir de la Mer » par les Ottomans, « Miramar » par les marins du Nord. Cette demeure ostentatoire dans laquelle le Colonel rêve de vivre avec sa femme et ses enfants le fascine.

Une admirable entrée en faïences de couleur améthyste qui, oui, oui, m’a beaucoup fait penser à tes yeux. On accède par un petit escalier à une merveilleuse cour marbrée ouverte sur le ciel, et quel ciel ! Un puits de lumière. Une fontaine centrale du plus joli effet dont on devine qu'il y a peu de temps coulait encore une eau musicienne. Des galeries en arcatures 
telles des mosquées la cernent. Des faïences incomparables par leurs teintes pastel, vieillies, ravissantes. Je nous imagine, alanguis durant la sieste, dans un profond sofa. (Saadi, 2000, p. 138)

Par conséquent, le colonel l'achète et y vit avec sa femme Madame Saint-Aubin, son fils Jacques et sa fille Marie-Victoire. Peu après, les enfants retournent à Paris pour poursuivre leurs études. Marie-Victoire qui étudie le droit aime beaucoup Alger mais Jacques pense que «la vie, c'est Paris » (Saadi, 2000, p. 163).

Le colonel qui reste avec sa femme à Alger veut voir Marabout dont les ancêtres sont enterrés à côté de la maison. Il lui dit qu'il ne touche pas au cimetière des parents de Marabout parce qu'il est une personne respectueuse des coutumes des Algériens. De surcroît, il veut que Marabout qui perd son bras droit dans l'explosion d'une mine en France s'occupe du jardin de la maison. Ici, il convient d'ouvrir une parenthèse pour rappeler les différences entre colons et colonisés. Le colonel et Marabout perdent leur bras mais le colonel porte une prothèse alors que Marabout a un simple crochet (Saadi, 2000, p. 295).

Marabout accepte la proposition d'Albin Saint-Aubin et au cours du temps, une relation étroite s'établit entre les deux. Contrairement aux colons, le colonel ne méprise jamais les Algériens et parle souvent avec Marabout de l'histoire de la maison, des habitants du Village indigène, de leurs activités et de leurs origines pendant que Marabout, la main verte, s'occupe du jardin. Le colonel fait tellement confiance à Marabout qu'il lui dit : "Tu es la clé de la Maison » (Saadi, 2000, p. 167). De plus, il lui donne la parcelle de terrain qu'il cultive. Marabout qui raconte cet évènement à son fils après des années est heureux comme le premier jour : «[...] j'ai prié : Hamdoullilahi. J'étais le premier Ouakli à posséder un lopin de terre. Possédant sans titre mais terre [...] 》 (Saadi, 2000, p. 199).

Albin Saint-Aubin soutient également les revendications des Musulmans qui veulent se débarrasser des Français. Alors, il demande sa retraite car il ne veut pas combattre contre les Algériens qu'il aime comme ses frères. En plus des Algériens, il aime aussi Alger et veut être enterré dans le cimetière accolé à la maison. Tous ces exemples prouvent qu'une vraie relation est établie entre la culture regardée et regardante. 


\section{Blanche}

Le Colonel Albin Saint-Aubin qui ne veut pas combattre contre les Algériens rentre en France et sa fille, Marie-Victoire, épouse un militaire français, M. Bernard et s'installe dans la maison. Marabout qui possède son propre terrain dans cette maison continue de s'occuper du jardin.

Pendant cette période où la fille du colonel vit avec son mari dans « Miramar » la relation entre cette famille française et Marabout est renforcée. Par exemple, lorsque la femme de Marabout est sur le point d'accoucher, M. Bernard l'emmène à I'hôpital avec sa voiture. Le fils de Marabout, Rabah, est « [...] le premier Ouakli à naître en dehors de Miramar. Dans un hôpital » (Saadi, 2000, p. 180). Marie-Victoire aime beaucoup Rabah et passe parfois du temps avec lui dans le jardin. Mais son intérêt commence à diminuer petit à petit quand ses propres enfants naissent.

La naissance de Blanche puis de son frère Arthur, je les avais vécues comme un malheur. Mme Marie-Victoire qui s'intéressait auparavant à moi, m'offrant souvent du chocolat au lait lorsque j'accompagnais Marabout lors de ses travaux au jardin, semblait ne plus me regarder, ses yeux attentionnés désormais pour ces enfants. Et je les enviais d'être traités comme des gosses de reine, blonds comme les blés, toujours bichonnés, au milieu de poupées et de jouets, et peu à peu, sans qu'il le comprenne, je trouvais trente-six prétextes pour ne plus accompagner mon père à Miramar. (Saadi, 2000, p. 201)

Contrairement au fils de Marie-Victoire, sa fille, Blanche adore Alger et se lie d'amitié avec Rabah dès son enfance. Cependant, il y a de grandes différences entre eux car Rabah ne connaît pas les coutumes et les traditions françaises. Par exemple, Rabah voit plusieurs fois que Blanche et sa famille écoutent « une langoureuse mélodie » (Saadi, 2000, p. 206) qu'il n'entend jamais à la radio. C'est Blanche qui lui explique que c'est de l'opéra. De plus, Rabah trouve étrange que Blanche porte un maillot de bain et se fasse bronzer avec ses cousins et cousines. Malgré les différences culturelles entre eux, Blanche et Rabah s'aiment. Mais elle doit quitter l'Algérie à cause de la guerre d'indépendance algérienne. 
À Paris, Blanche qui aime beaucoup à la fois Rabah et l'Algérie soutient l'indépendance de l'Algérie (Saadi, 2000, p. 272). Elle ne se sent jamais comme chez elle en France parce que l'Algérie est sa patrie alors que la France, c'est la France pour elle. Pour cette raison, suite à l'indépendance, elle rentre tout de suite en Algérie parce qu'elle apprend que le gouvernement algérien commence à recruter des professeurs de français.

[...] Je ne suis ici ni pour des pierres ni pour des reliques du passé. Je vis dans cette Maison parce qu'elle vit en moi, dans les parfums du jardin qui me parviennent le soir, dans l'ombre ciselée que forme le palmier sur les tombes, dans l'éblouissement de la vérité du ciel au-dessus du patio. C'est cela ma terre, c'est mon pays... (Saadi, 2000, pp. 262-263)

Blanche retrouve à la fois son enfance et son amour inachevé. Quand elle et Rabah commencent à vivre leur amour, apparaissent des manifestations « pour exiger du gouvernement d'appliquer la charia » (Saadi, 2000, p. 265). Dans cette période compliquée, Blanche ressent d'hostilité autour d'elle ; au lycée, certains de ses collègues cessent de parler dès qu'ils la voient, d'autres ne veulent pas lui serrer la main. De surcroît, quand elle passe en voiture, elle reçoit « des pierres sur son pare-brise » (Saadi, 2000, p. 279). Lorsque les manifestations se multiplient, une lettre lui arrive : « Le Consul général de France en Algérie, vivement inquiet de la sécurité de nos ressortissants, vous recommande très vivement de quitter votre domicile dans les meilleurs délais [...] » (Saadi, 2000, p. 279).

Elle la déchire et n'en parle pas à Rabah qui est sûr qu'elle doit partir. Elle choisit de rester mais peu de temps après, elle reçoit deux balles dans la tête et meurt. Elle est enterrée à côté des ancêtres de Rabah. Comme le montrent les exemples ci-dessus, Blanche aime l'Algérie et la considère comme sa propre patrie. Elle établit une relation étroite avec les Algériens comme son grand-père. Il est exact qu'une vraie relation se trouve entre Je et l'Autre mais la mort de Blanche révèle aussi qu'il y a une haine, en d'autres termes, la différenciation entre les deux cultures.

\section{La culture de l'Autre}

À la fin de la deuxième étape, Daniel-Henri Pageaux propose d'analyser « le système de valeurs de l'Autre, les expressions de sa culture au sens anthropologique, ce qui 
permet d'ailleurs de plus ou moins larges descriptions ou séquences narratives : pratiques artistiques, religion, musique, vêtement, cuisine, etc. » (Pageaux, 1994, p. 68).

Parmi les éléments culturels, la langue, la religion, l'art et l'histoire de l'Autre sont généralement mentionnés dans le roman. En ce qui concerne la langue de l'Autre, elle est tenue par l'écrivain et sa société pour inférieure à la culture regardante car les Algériens ne peuvent pas facilement l'adopter ; c'est une langue rocailleuse et difficile à apprendre (Saadi, 2000, p. 131, 204) pour eux.

Dans le roman, l'écrivain insiste sur la religion des Français. Alors qu'il dépeint la conquête de l'Algérie par les Français, il préfère les appeler « Chrétiens » plutôt que « Français » : « des navires chrétiens » (Saadi, 2000, p. 65), «l'arrivée des chrétiens » (Saadi, 2000, p. 66), « [...] quand les armées des chrétiens envahissaient les douars, Dieu transformait les habitants en oiseaux pour les protéger » (Saadi, 2000, p. 69).

Bien qu'il y ait des gens qui croient en d'autres religions en Algérie pendant cette période, le nombre des Musulmans ne peut pas être sous-estimé. Comme on le sait, le porc est un aliment interdit en Islam. Pour cette raison, les Algériens réagissent contre les Français qui apportent des cochons avec eux. Étant donné qu'aux yeux des Algériens, le cochon est une « bête immonde » (Saadi, 2000, p. 79), ils évitent le contact avec cet animal et refusent « de débarquer la bête immonde » (Saadi, 2000, p. 80).

Un autre élément culturel qui a une place aussi importante que la langue et la religion est l'art. L'intérêt des Français pour l'art est souligné dans le roman. Par exemple, parmi les colons, il y a également un professeur, Charles Lenoir, qui a « mission d'étudier et de répertorier tous les monuments, les palais, les demeures cossues, les mosquées, les cimetières afin que tout soit classé, protégé » (Saadi, 2000, p. 81). De plus, les Français font une statue d'un général français à Alger. Mais ils l'emportent après l'indépendance (Saadi, 2000, p. 152).

Il est bien connu que I'histoire est également un élément culturel d'une nation. Dans le roman, I'histoire française est fréquemment racontée. L'histoire coloniale de la France, I'affaire Dreyfus, celle de Stavisky, I'Alsace-Lorraine, Charles de Gaulle sont tous expliqués. Tous ces exemples démontrent que le livre de Saadi contient de nombreuses images de la culture française et montre la culture de l'Autre à ses lecteurs. 


\section{Les attitudes des algériens}

La dernière étape de l'approche imagologique de Pageaux est « un moment herméneutique » (Pageaux, 1994, p. 68). Dans cette phase, il faut révéler les attitudes des Algériens envers les Français en se basant sur les résultats des analyses faites cidessus. En d'autres termes, les images des Français inscrites dans la conscience du peuple algérien sont expliquées. Dans ce contexte, Pageaux divise l'image de l'Autre en quatre attitudes fondamentales; la manie, la phobie, la philie et la cosmopolite ou internationaliste.

[...] l'individu peut considérer la culture observée inferieur à la sienne ou, par contre, supérieur, attitudes qui sont à l'origine de ce que l'auteur désigne par « phobie » ou « manie » et qui impliquent, respectivement, une attitude de " dévaluation » ou de "valorisation » par rapport aux références culturels du sujet. Celui-ci peut aussi développer une attitude qui consiste à valoriser la culture de l'Autre, sans, quand même, minoriser sa propre culture. Cette manifestation, que l'auteur désigne par « philie », est plus équilibrée, car elle n'implique ni l'excessive importation de modèles étrangers (ce qui caractérise la « manie »), ni sa complète négation, ce qui est propre de la « phobie ». La quatrième attitude - la cosmopolite ou internationaliste -, se manifeste au moment où le sujet essaye de se débarrasser de ses propres références culturelles face à une réalité étrangère, tout en affirmant son cosmopolitisme et en assumant une vision universaliste, dans une tentative de comprendre dans son ensemble la diversité culturelle de l'étranger. (Cabete, 2010, p. 7)

Les analyses fondées sur la perception de l'Autre et de sa culture par Je, autrement dit, par la culture regardante, montrent que l'écrivain définit les Français en utilisant à la fois des images positives et négatives dans son livre. Il est certain que la culture regardée est parfois tenue par l'écrivain comme supérieure à la culture regardante et une relation étroite est établie entre les Français et le peuple algérien. Cette situation est appelée la manie selon Pageaux parce que « la représentation de l'étranger relève plus d'un mirage que d'une image » (Pageaux, 1994, p. 71). En revanche, comme déjà indiqué, il existe aussi des images négatives des Français. Cette fois, l'attitude des Algériens est la phobie parce que « la réalité étrangère est tenue pour inférieure par rapport à la supériorité de la culture d'origine » (Pageaux, 1994, p. 71). Finalement, il 
est possible d'appeler la relation entre l'Autre et Je à la fois la manie et la phobie selon Daniel-Henri Pageaux.

\section{Conclusion}

Étant donné que l'imagologie vise à afficher l'image d'une nation dans la littérature d'une autre nation, les études imagologiques révèlent les réflexions sur l'Autre et donnent l'occasion de découvrir les idées d'un écrivain et de sa société sur un groupe, une société ou une nation à travers des images. En d'autres termes, on peut pénétrer au cœur des événements racontés dans les textes littéraires grâce aux images que l'auteur utilise pour écrire l’Autre.

Il est envisageable que ce travail dévoile les pensées de Nourredine Saadi et du peuple algérien sur les Français par le biais des personnages et des évènements dans le roman intitulé La Maison de lumière. Il est exact que ce livre offre de nombreuses images de l'Autre. Pour cette raison, le contexte historique, les réalités sociales, les logiques spatiale et temporelle, les caractéristiques de la culture de l'Autre, la question de la différence culturelle sont identifiés dans ce travail. Les analyses illustrent donc que les Français/l'Autre, ont des images à la fois positives et négatives dans la conscience du peuple algérien. Les exemples ci-dessus révèlent qu'il existe une relation étroite entre la culture regardée et la culture regardante et certains Algériens aiment vraiment les Français qu'ils vivent ensemble pendant de longues années. Par contre, dans certains cas, les Algériens ne sont pas contents de vivre avec les Français parce que ceux-là pensent que les Français prennent le contrôle de leur propre pays.

Pour conclure, il est possible de dire que les personnages - la culture regardée l'Autre - les Français sont parfois considérés comme supérieurs et parfois inférieurs par l'écrivain - le narrateur - la culture regardante - les Algériens dans le roman de Saadi. En bref, la perception de l'Autre montre, dans ce roman, à la fois une attitude de « valorisation » et de « dévaluation » quand on regarde l'Autre à travers le prisme de Nourredine Saadi. 
Évaluation : Évaluation anonyme par des pairs extérieurs.

Conflit d'intérêts : L'auteure n'a aucun conflit d'intérêts à déclarer.

Subvention : L'auteure n'a reçu aucun soutien financier pour ce travail.

Peer-review: Externally peer-reviewed.

Conflict of Interest: The author has no conflict of interest to declare.

Grant Support: The author declared that this study has received no financial support.

\section{Bibliographie}

Brachfeld, O. (1962). Note sur l'imagologie ethnique. Revue de Psychologie des Peuples, pp. 34-45.

Cabete, S. M. C. (2010). Le récit de voyage au Portugal au XIX'me siècle : altérité et identité nationale [en ligne]. (Thèse de doctorat). Université nouvelle de Lisbonne et Université Sorbonne Nouvelle Paris III. https://tel.archivesouvertes.fr/tel-00868637/file/2010PA030055_2.pdf, consulté le 21 avril 2020.

Chevrel, Y. (2009). La littéraire comparée. Paris : PUF.

Chikhi, B. (1997). Littérature algérienne désir d'histoire et esthétique. Paris : L'Harmattan.

Fanon, F. (2002). Les Damnés de la terre. Paris : La Découverte/Poche.

Ferro, M. (1994). Histoire des colonisations : des conquêtes aux indépendances (XIII - XXe siècles). Paris : Seuil.

Moura, J. M. (1998). L'Europe littéraire et l'ailleurs. Paris : PUF.

Moura, J. M. (1992). Lire l'exotisme. Paris : Dunod.

Memmi, A. (1973). Portrait du colonisé précédé du Portrait du colonisateur. Paris : Payot.

Pageaux, D. H. (1994). La littérature générale et comparée. Paris : Armand Colin.

Pageaux, D. H. (1995). Recherche sur l'imagologie : de l'Histoire culturelle à la Poétique. Revista de Filologia Francesa, 8, pp. 135-160.

Saadi, N. (2000). La Maison de lumière. Paris : Albin Michel.

Said, E. (2005). L'orientalisme : L'Orient créé par l'Occident. (C. Malamoud, Trad.). Paris : Seuil.

Ulağlı, S. (2018). 'Öteki'nin bilimine giriş: Imgebilim. Istanbul : Motto Yayınları. 